\title{
Article \\ Experimental Study of Thermal Comfort Based on Driver Physiological Signals in Cooling Mode under Summer Conditions
}

\author{
Yunchan Shin ${ }^{1}$, Jeonggyun Ham ${ }^{1}$ and Honghyun Cho ${ }^{2, *(\mathbb{D}}$ \\ 1 Department of Mechanical Engineering, Graduate School of Chosun University, 303 Pilmun-daero, Dong-gu, \\ Gwangju 501-759, Korea; sinyc17@chosun.kr (Y.S.); orchiders@chosun.kr (J.H.) \\ 2 Department of Mechanical Engineering, Chosun University, 303 Pilmun-daero, Dong-gu, \\ Gwangju 501-759, Korea \\ * Correspondence: hhcho@chosun.ac.kr; Tel.: +82-62-230-7050; Fax: +82-62-230-7055
}

Citation: Shin, Y.; Ham, J.; Cho, $\mathrm{H}$. Experimental Study of Thermal Comfort Based on Driver Physiological Signals in Cooling Mode under Summer Conditions. Appl. Sci. 2021, 11, 845.

https://doi.org/10.3390/ app11020845

Received: 29 December 2020

Accepted: 14 January 2021

Published: 18 January 2021

Publisher's Note: MDPI stays neutra with regard to jurisdictional claims in published maps and institutional affiliations.

Copyright: (C) 2021 by the authors Licensee MDPI, Basel, Switzerland. This article is an open access article distributed under the terms and conditions of the Creative Commons Attribution (CC BY) license (https:// creativecommons.org/licenses/by/ $4.0 /)$.

\begin{abstract}
In this study, electroencephalogram (EEG), photo-plethysmography (PPG), and surface temperature measurements of subjects were taken while performing a driving simulation when the cabin and vent discharge air temperature in summer were changed from discomfort to comfort conditions. Additionally, subjective questionnaires were used to analyze the subject's thermal comfort under the various driving environments. As a result, the surface temperatures of the forehead, left hand, right hand, and abdomen of the subject during driving were reduced by 2, 0.97, 2.18, and $5.86{ }^{\circ} \mathrm{C}$, respectively, by operating a $12.5^{\circ} \mathrm{C}$ vent cooling function at a cabin temperature of $35^{\circ} \mathrm{C}$. As a comprehensive analysis of the subjective survey, PPG, and EEG results, total power (TP), the standard deviation of N-N interval (SDNN), and the root mean square of successive differences (RMSSD) of subjects increased and stress index decreased at cabin and vent discharge air temperatures of 30-27.5 ${ }^{\circ} \mathrm{C}$ and $16.5-18.5^{\circ} \mathrm{C}$, respectively. Furthermore, the relative sensory motor rhythm (SMR) wave and concentration index $(\mathrm{CI})$ of the frontal lobe tended to increase under the same temperature conditions. Accordingly, it was confirmed that these temperature conditions provided a pleasant driving environment for the driver and increased concentration on driving.
\end{abstract}

Keywords: electroencephalogram (EEG); mean surface temperature (MST); solar radiation; photoplethysmography (PPG); stress index

\section{Introduction}

As industry has developed, transportation technologies have also developed. Car ownership has reached more than one car per household in some developed countries. The automobile has become indispensable, and it is recognized as another living space, beyond being a means of transportation. Consequently, many parts of the vehicle are rapidly changing from simple mechanical systems to electric, electronic, and control systems for the safety and comfortable of the occupants. Many companies are in the process of developing autonomous vehicles, and they intend to commercialize these within 10 years. In addition, many technologies have been developing rapidly because of increasing levels of investment in key technologies related to autonomous vehicles [1,2]. In the case of self-driving cars, the most important issue safety; however, it is also important to provide a comfortable environment to the drivers and passengers, while managing and optimizing the energy of the car simultaneously. Because the heating, ventilating, and air-conditioning (HVAC) system in an electric vehicle uses electricity, the air flow and temperature distribution in the car cabin are important for saving energy and providing effective cooling or heating. Therefore, the development of, and smart control method for, efficient automobile airconditioning systems are required [3].

As environmental problems, such as fine dust and pollution, that threaten the comfort of humans have emerged, the thermal comfort of the driver of the automobile has become 
more important. In particular, solar energy passing through the window of a car during the summer increases the temperature inside a car significantly and transmits radiant energy directly to the driver, providing a great discomfort to the driver. In addition, the incidence of traffic accidents resulting from driver discomfort or drowsiness when a car is driven for a long time in the summer is increasing. Moreover, excessive use of air conditioners in a car can cause health problems for passengers [4]. Therefore, a great deal of information is needed to optimize the control of the HVAC system to provide a comfortable environment and improve the concentration of drivers and passengers. However, because the flow direction of the cold air, the temperature and outlet speed of the discharged air, and the amount of external solar radiation change continuously, the indoor environment of the car is more complex and unpredictable than that of buildings or offices [5]. It is important to provide an appropriate thermal comfort environment to the driver by using a HVAC system, even though the thermal environment of the vehicle changes constantly; however, it is difficult to create an optimal environment with an effective control method through experimentation with a real system.

In previous studies on building thermal comfort, Yao et al. [6] investigated three physiological parameters-skin temperature (local and average), electrocardiogram (ECG), and electroencephalogram (EEG) - to determine the relationship between ambient temperature and thermal comfort. They reported that the average skin temperature increased, while the maximum difference between the local skin temperature decreased when the ambient temperature increased from 21 to $29^{\circ} \mathrm{C}$. In addition, the average skin temperature for a neutral heat sensation was approximately $32.1^{\circ} \mathrm{C}$, and the maximum difference of the local skin temperature was $5.3^{\circ} \mathrm{C}$. Ciuha et al. [7-9] investigated the difference in skin sensitivity in response to the change of temperature stimulation in recognition of thermal comfort. They reported that regional differences in the boundaries and size of the thermal comfort zone in a comfortable environment $\left(33^{\circ} \mathrm{C}\right)$ between male and female subjects were not present.

Lai et al. [10] studied the dynamic thermal comfort in an outdoor environment, and they showed that the local skin temperature of the human body in a cold environment did not decease $\left(34^{\circ} \mathrm{C}\right)$ because of strong heat insulation and a large heat capacity. Moreover, it was confirmed that the temperature of the face was relatively low $\left(19^{\circ} \mathrm{C}\right)$. They developed a human body heat transfer model according to the outdoor thermal environment. Chang et al. [11] investigated the effects on the EEG of subjects in response to warm and cold stimulation. They confirmed that specific EEG activation occurred during warm and cold stimulation.

Because most previous studies on thermal comfort have been conducted inside buildings/indoors, the experiments on thermal comfort were carried out in conditions in which the range of temperature change in the space was not large. In addition, experimental studies on temperature control methods were mostly conducted to provide a comfortable thermal environment according to the type of air conditioner. Unlike in buildings, the indoor thermal environment of automobiles is affected by various factors, such as solar radiation, external air temperature, low-temperature air temperature from the HVAC system, and complicated air flow. Thus, further studies that consider these factors are required.

In a previous analytical study on thermal comfort in an automotive thermal environment, Hodder et al. [12] performed an analysis of heat flow in the interior of a vehicle in consideration of solar radiation to determine the effects of the spectral type of sunlight and the physical properties (absorption rate, transmittance, etc.) of the glass on thermal comfort. When the body was exposed to a simulated solar radiation of $400 \mathrm{~W} / \mathrm{m}^{2}$, the spectral content of the radiation did not affect the thermal sensation. Furthermore, the thermal comfort vote increased by one scale at an increase of $200 \mathrm{~W} / \mathrm{m}^{2}$ of solar radiation. Chien et al. [13] studied the validity of analysis results based on experimental results and analyzed thermal comfort using the predicted mean vote (PMV) evaluation method to investigate the thermal environment inside the vehicle. It was confirmed that, after the air conditioner was turned on, the average temperature in the car interior rapidly decreased, 
and the PMV value at $1200 \mathrm{~s}$ resulted in discomfort being reported only for the feet. Martinho et al. [14] measured the temperature and airflow velocity around the human body both experimentally, and through modeling. They evaluated thermal comfort using the equivalent homogeneous temperature method. A significant difference was found in the calculated equivalent temperature based on the maximum and minimum air velocities of the approximate planes at each body part. They also reported that this corresponded to a body part located in a place directly affected by jets from the air intake, which generated a high local air velocity gradient.

Lin et al. [15] analyzed the thermal environment in an automobile interior according to the flow rate and location of the air conditioner outlet, and it was confirmed that the location of the air conditioner vent and the airflow of the total system are the most important parameters directly affecting thermal comfort. In addition, the solar heat load, which is the main heat source of the passenger compartment, could be reduced by the characteristics of the glass material. Kobayashi et al. [16] measured local thermal sensation for four cases of air flow to the head, head and foot, chest, and chest and foot and compared them with Zhang's model. It was confirmed that the evaluation of local thermal sensation by Zhang's model had a high accuracy. However, the estimation of overall sensation and local/overall comfort was still inaccurate and needed significant improvement. Zhang et al. $[17,18]$ performed an analysis of the thermal environment inside an automobile and compared experimental and numerical analysis results. They reported that the predicted temperature matched the experimental one well, and the temperature distribution of the simulation model was also similar to that of the experimental one.

In previous experimental research on thermal comfort in an automotive thermal environment, Zhou et al. [19] and Qi et al. [20] investigated the thermal comfort of automobile passengers under indoor parking, outdoor parking, and outdoor driving conditions during summer. They reported that the internal air and surface temperatures of a vehicle were temporarily nonuniform, and the surface temperature in outdoor driving conditions changed more quickly than that in indoor and outdoor parking because of the rapid change of solar radiation. Jung et al. [21] investigated the effects of individual responses on individual thermal comfort sensitivity and collective control according to temperature change. They confirmed that thermal comfort sensitivity had a statistically important role in group conditioning. Among the evaluated scenarios, in $85.9 \%$ of the cases (134 out of 152), statistically significant differences in temperature set points were observed in consideration of thermal comfort sensitivity, but the probability of having a comfortable state increased overall.

Kristanto et al. [22] performed a simulation study on the sensitivity of energy conversion to air quality, thermal comfort, and energy consumption in automobile interiors. They reported that the use of a cover for parking could reduce the windshield transmittance by $5 \%$ and decreased the PMV by $0.9 \%$. In addition, the thermal comfort and the energy consumption could be increased by controlling the supply air volume and temperature. Alahmer et al. [23-25] evaluated temporal and non-uniform changes of vehicle interior temperature and relative humidity, as well as changes in the skin temperatures of the driver in the forehead, hands, and feet. They confirmed that the control of relative humidity during the heating and cooling process by the air-conditioning system could produce a comfortable environment more quickly than when the relative humidity was not controlled.

In addition, in the experimental studies of bio-signal measurement for thermal comfort in an automotive environment, Ting et al. [26] and Tsutsumi et al. [27] quantified the fatigue progress of the driver using multipurpose and subjective measurements. A principal component analysis was used to measure the temporal decrease in driver performance from an alert state to a fatigued state using various measurements of driving performance throughout the experiment. They reported that $80 \mathrm{~min}$ was the limitation of safety in monotonous highway driving. Shin et al. [28,29] measured the bio-signals of the driver during heating and cooling by the HVAC system, and they reported that the cabin and vent outlet air temperatures should be set to 27.5 and $18.5^{\circ} \mathrm{C}$, respectively, to improve driver comfort and concentration in cooling mode without solar radiation. In heating 
mode, cabin and vent outlet temperatures of 25 and $30{ }^{\circ} \mathrm{C}$ were ideal. Ikenishi et al. [30] investigated the driver EEG parallel factors while driving a car, and they reported that the driver preferentially recognized the shape and color more than the distance and motion of a vehicle during driving. Yang et al. [31] predicted driving behaviors based on EEG results under various traffic conditions using a simulation method. They found that the average classification accuracy of prediction was $69.5 \%$ and the highest accuracy was $83.5 \%$. In addition, there was a significant correlation between the EEG pattern and car-following behavior.

Most previously published studies on the thermal comfort in automobiles are analytical studies, and most experimental studies on the thermal comfort of drivers have been conducted by measuring only one of the bio-signals of the driver or passenger. However, it is difficult to investigate driver thermal comfort accurately by using only a single bio-signal, and the uncertainty of the experiment is high. In addition, because the condition of the driver can be comprehensively analyzed by simultaneously measuring various biological signals, such as brain waves, pulse waves, and skin temperature, the thermal comfort can be objectively and effectively investigated. Therefore, further studies based on comprehensive data on the bio-signals of drivers under various conditions are urgently needed. Although the effect of solar radiation on the indoor environment of automobiles has a significant effect on drivers, experimental research is still insufficient, and there has been no objective research to define the thermal comfort of drivers according to operating conditions. Therefore, in this study, to simulate the interior of a car during a hot summer day, the temperature and humidity were controlled in a thermal environment chamber, and a solar simulator was also used to simulate the solar radiation condition. In this environment, the bio-signals-EEG, photo-plethysmography (PPG), and skin temperature-of the subject were measured, and subjective surveys-thermal sensation vote (TSV), comfort sensation vote (CSV), and concentration level vote (CLV) - were conducted to investigate the thermal comfort of the driver under solar radiation according to the discharge air temperature of the vent and cabin temperature. The results of this study are considered to provide basic data to increase the thermal comfort of the driver and passenger in a car and can be applicable to future vehicles, such as electric and autonomous vehicles.

\section{Experimental Setup and Methods}

\subsection{Experimental Setup}

Figure 1 shows a schematic diagram of the experimental setup. The experiment was conducted in a simulation room inside a psychrometric chamber. The rear part of the driver's seat in the car was removed, and only the air-conditioning system in front of the driver and devices for driving were installed. The temperature and humidity of the psychrometric chamber were controlled to match the change in indoor temperature in the car. The discharged air temperature from the HVAC vent was controlled based on the vent outlet air temperature of the air-conditioning system in an actual vehicle. To simulate the inside of a car, an HVAC of a 2000 cc vehicle was installed in front of the driver's seat, and airflow was supplied to the simulation room so that the subject could feel an environment similar to that in a real vehicle. In addition, to investigate accurately the thermal environment in the car interior, three vent discharge temperatures were measured simultaneously. Furthermore, the temperature of the air inside the room was measured using nine T-type thermocouples at the upper, middle, lower, left, center, and right sides in the space behind the driver's seat. Artificial solar lighting (Technox, Inc.) was used to supply solar radiation to investigate the effect on driver thermal comfort during driving during summer. Table 1 shows the detailed specifications of the solar simulator. To calculate the amount of solar radiation applied to the driver, the solar radiation was measured on the driver's surface using a solar radiation meter. The specifications of the measuring device used in this study to measure the air temperature and solar radiation are presented in Tables 2 and 3. Similarly, to consider the effect of solar radiation from the sun on the driver in a car, a solar light was installed with an angle of $60^{\circ}$ from the front left to the 
driver. The irradiated area and the amount of insolation on the surface of the subject were measured with a $3 \mathrm{~cm}$ grid, and the amount of solar energy on the surface of the subject was calculated based on a numerical integration method using an average proximity value. As a result of the measured solar radiation, the maximum amount of solar radiation on the body of the subject was $1251 \mathrm{~W} / \mathrm{m}^{2}$, and the average amount of solar radiation on the body surface of the driver was calculated to be approximately $526 \mathrm{~W} / \mathrm{m}^{2}$.

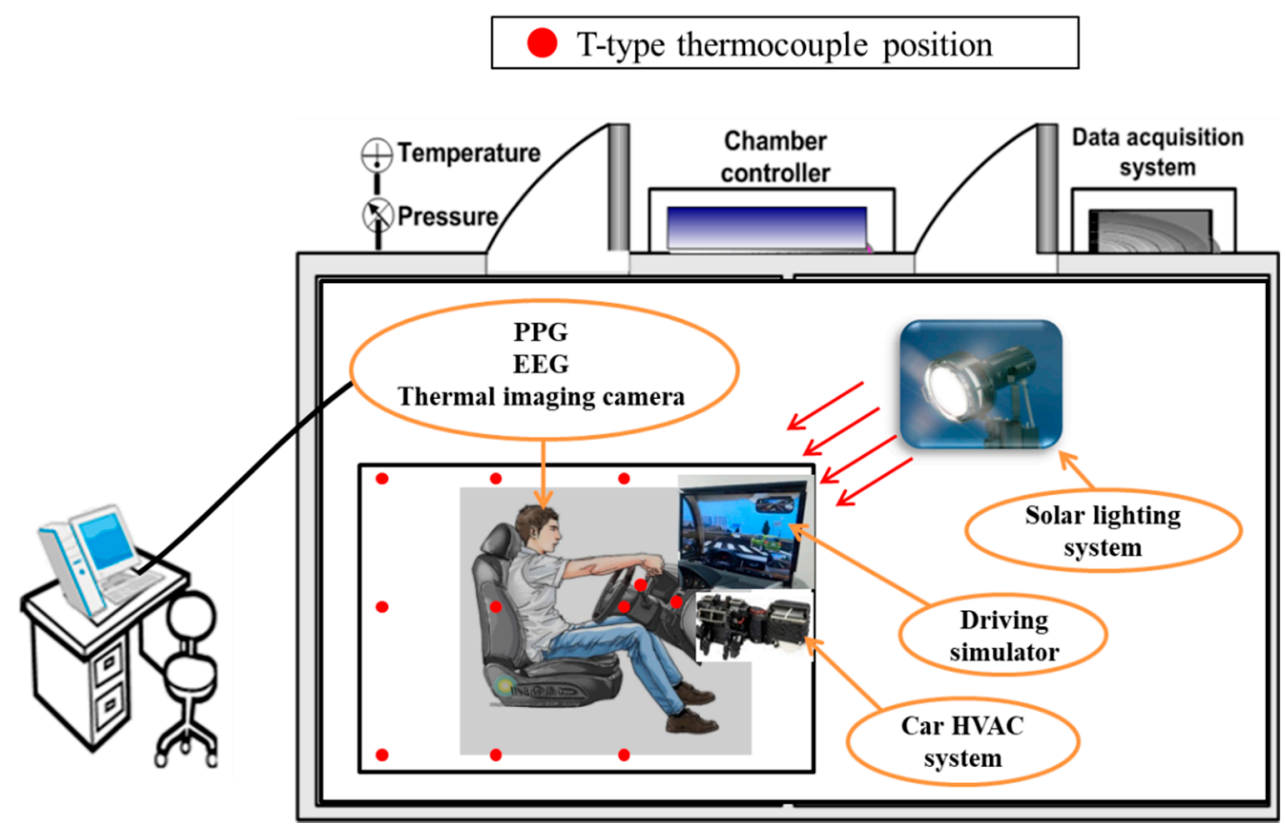

Figure 1. Schematics of experimental room. PPG: photo-plethysmography; EGG: electroencephalogram; HVAC: heating, ventilating, and air-conditioning.

Table 1. Specification of solar lighting device.

\begin{tabular}{cc}
\hline Item & Specification \\
\hline Model & XC-500E \\
Filter & Transparency \\
Lamp capacity & $500 \mathrm{~W}$ \\
Center luminous intensity & $26,000 \mathrm{~cd}$ \\
Luminescence wavelength band & $350-2500 \mathrm{~nm}$ \\
\hline
\end{tabular}

Table 2. Specification of thermocouple.

\begin{tabular}{cc}
\hline Item & Specification \\
\hline Type & T-type \\
Range & $-200-300{ }^{\circ} \mathrm{C}$ \\
ANSI standard limits of error & $0.75 \%$ \\
ANSI special limits of error & $0.40 \%$ \\
\hline
\end{tabular}

Table 3. Specification of solar radiation meter.

\begin{tabular}{cc}
\hline Item & Specification \\
\hline Type & $\mathrm{CR}-110$ \\
Storage environment temperature & From $-10-70{ }^{\circ} \mathrm{C}$ \\
Range & $0-1500 \mathrm{~W} / \mathrm{m}^{2}$ \\
Precision & $5 \%$ of reading \\
\hline
\end{tabular}




\subsection{Driving Simulator and Bio-Signal Measurement Device}

An experiment was conducted using a driving simulator to provide the subject with an environment similar to a real driving condition. The driving simulator used a G27 racing wheel (Logitech, Inc.) and driving simulation software (City Car Driving 1.5, Forward Development, Inc.) was used. To measure the variations in the physiological signals according to changes in the indoor temperature and vent discharge air temperature of the vehicle during driving, the physiological signals of the drivers were measured and analyzed by installing EEG and PPG measuring equipment and a thermal-imaging camera. The pulse wave (PPG) was measured using uBioMacpa (BioSense Creative, Inc.), which is an optical volume pulse wave device using infrared rays. During the experiment, subjects abstained from excessive movement for the precise measuring of bio-signals.

Figure 2 shows a picture of a worn pulse wave measuring device, and Table 4 shows the specifications of the pulse wave measuring device. The pulse wave is a waveform representing the vascular volume fluctuations transmitted to the peripheral arteries, and it is possible to investigate the conditions of autonomic nerve balance, stress index, and heart rate distribution by using the analysis of the pulse wave. The stress index can be displayed by analyzing the range of autonomic nerve rhythm, and the autonomic nerve balance (LF (low frequency)/HF (high frequency)) is the ratio of sympathetic activity to parasympathetic activity. It is also an index of immunity of the body. Total power (TP) indicates the epidemic fever of the patient. When it is lower than the normal value, it means that the autonomic nerve control ability and the immunity decreased, and the ability to regulate against the external environment and the ability to respond to stress decreased. In addition, the standard deviation of N-N interval (SDNN) indicates the standard deviation of the pulse from the external environment. When it increases, the condition of subject is stable. Using the root mean square of successive differences (RMSSD) is a method to check the parasympathetic activity by evaluating the mean deviation of the heartbeat.

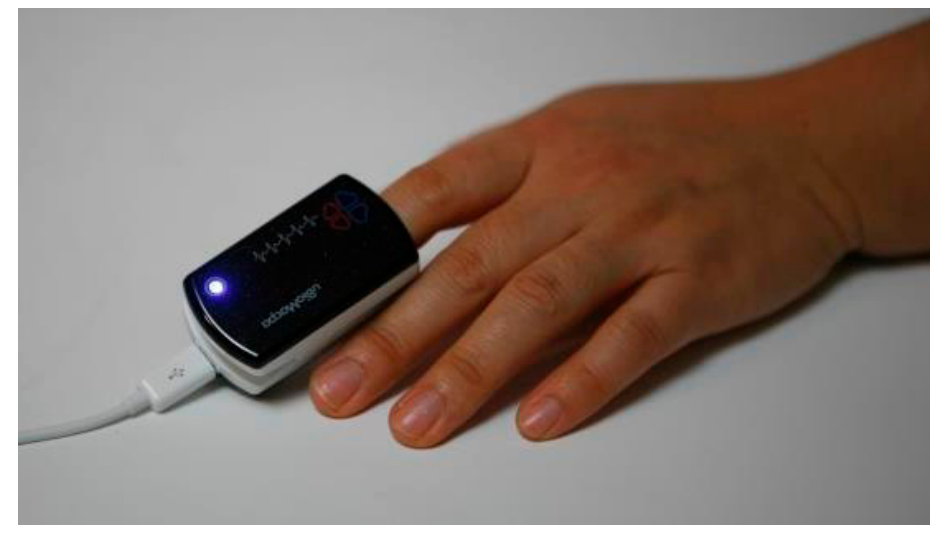

Figure 2. Image of the PPG measurement.

Table 4. Specifications of the PPG measurement device.

\begin{tabular}{cc}
\hline Item & Specification \\
\hline Measuring range & $40-200 \mathrm{BPM}$ \\
Measurement error & $\pm 2 \%$ \\
Band pass filter & $0.15-4 \mathrm{~Hz}$ \\
\hline
\end{tabular}

Figure 3 shows the locations of the EEG measurement sensors mounted on the subject, and Table 5 represents the specifications of the EEG measurement equipment. The EEG measurement was performed using QEEG-16 (LAXTHA, Inc.), and it has an EEG cap with 16 measurement sensors according to the International 10/20 system. Fp1 and Fp2 are the prefrontal lobes, and F3, F4, F7, and F8 indicate the position of the prefrontal lobes. C3, C4, 
$\mathrm{P} 3, \mathrm{P} 4, \mathrm{P} 7$, and P8 are the positions of the parietal lobes, $\mathrm{T} 7$ and $\mathrm{T} 8$ are the temporal lobes, and $\mathrm{O} 1$ and $\mathrm{O} 2$ are the occipital lobes.

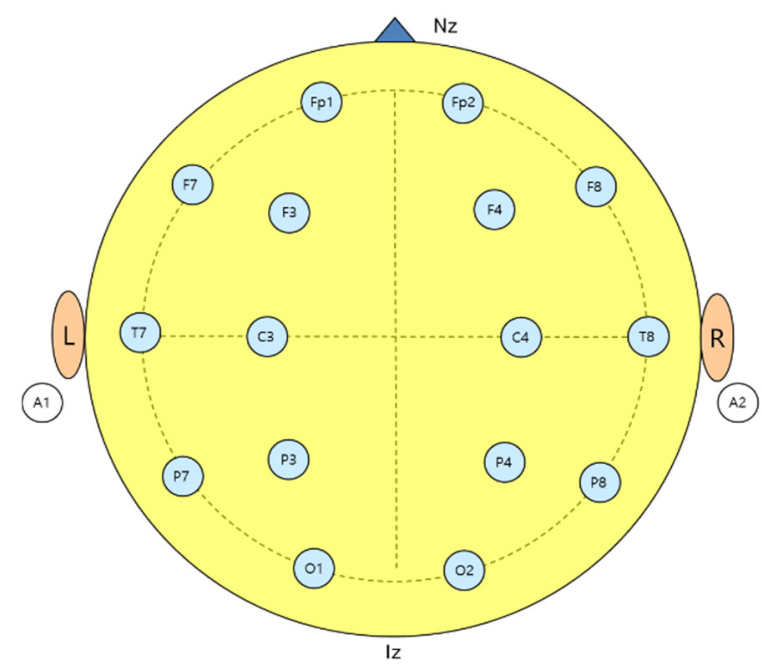

Figure 3. Image of electrode locations for EEG test.

Table 5. Specifications of the EEG measurement device.

\begin{tabular}{cc}
\hline Item & Specification \\
\hline Sampling rate & $256 \mathrm{~Hz}$ \\
Resolution & $12 \mathrm{bit}$ \\
Band pass filter & $0.5-60 \mathrm{~Hz}$ \\
Notch filter & $50-60 \mathrm{~Hz}$ \\
\hline
\end{tabular}

Human brain waves are roughly classified into $\delta-, \theta-, \alpha-, \beta-$, and $\gamma$-waves. The $\delta$-wave is 0.5 to $4 \mathrm{~Hz}$, and it appears in deep sleep and inner consciousness. The $\theta$-wave is 4 to $8 \mathrm{~Hz}$, and it is generated in sleepiness and shallow sleep. The $\alpha$-wave is $8-15 \mathrm{~Hz}$, and it occurs in a comfortable state or when the eyes are closed. In addition, the sensory motor rhythm (SMR) wave of the $\alpha$-wave is $12-15 \mathrm{~Hz}$, and it is generated in a slight state of tension, such as during attention and concentration. The $\beta$-wave is $14-30 \mathrm{~Hz}$, and it occurs in a state of concentration or anxiety and tension. The $\gamma$-wave is more than $30 \mathrm{~Hz}$, and it is present in anxiety and excitement. In this study, the $\beta / \alpha$-wave ratio was analyzed. A higher value means improved concentration because the $\beta$-wave increases. A lower value indicates a comfortable state because the $\alpha$-wave increases. In addition, a thermal-imaging camera was used to investigate the change in the surface temperature of the subject according to the operating condition. Table 6 shows the specifications of the thermal-imaging camera used.

Table 6. Specifications of the thermal-imaging camera.

\begin{tabular}{cc}
\hline Item & Specification \\
\hline Temperature resolution & CG640 \\
Temperature range & $50 \mathrm{mK} \cong \mathrm{f} 1.030 \mathrm{~Hz} 300 \mathrm{~K}$ \\
Temperature error & $\pm 2 \%$ \\
Spectral response & $8-14 \mu \mathrm{m}$ \\
\hline
\end{tabular}

\subsection{Definition and Condition of Subjects}

The group of subjects consisted of five males and five females. They were selected by using psychological and health status surveys. Moreover, they had more than one year of driving experience. All subjects were checked to ensure that they had no history of neuropsychiatric disorders, such as attention deficit disorder, epilepsy, or alcoholism. 
Other test results, such as electrocardiograms, were all normal. The experimental process was explained in detail through pretraining two days before the experiment to improve their understanding of it. In addition, to improve the accuracy of the experimental results, the subject was instructed to make sure they had enough sleep before the experiment. Intake of alcohol, nicotine, caffeine, and other drugs that could affect human cognitive function was restricted $6 \mathrm{~h}$ before the experiment. If it was determined that there would be difficulty proceeding with the experiment through a pretest on the day of the experiment, the experiment was postponed. Table 7 shows the average age and physical conditions of subjects of this study.

Table 7. Anthropometric data of the subjects.

\begin{tabular}{cccccc}
\hline Gender & $\begin{array}{c}\text { Number of } \\
\text { Subjects }\end{array}$ & Age & Weight (kg) & Height (m) & Body Area * $\left(\mathbf{m}^{\mathbf{2}}\right)$ \\
\hline Male & 5 & $27 \pm 2.8$ & $73.2 \pm 8.9$ & $172.8 \pm 4.9$ & $1.8 \pm 0.13$ \\
Female & 5 & $25 \pm 7.78$ & $59 \pm 7.78$ & $163.3 \pm 3.29$ & $1.63 \pm 0.12$ \\
\hline
\end{tabular}

${ }^{*}$ Body area calculated according to the method given by DuBois et al. [32].

Subjects body surface area was calculated by DuBois et al. [32], as shown in Equation (1).

$$
A_{d}=0.202 m^{0.425} l^{0.725}
$$

The subjects wore short-sleeved T-shirts and thin long pants based on the summer clothes of a general office worker. The amount of clothing was calculated by Equation (2), which was suggested by McCullough et al. [33].

$$
I_{\mathrm{clo}}=0.835 \sum_{I} I_{\mathrm{clo}, i}+0.161
$$

The average value of the individual amounts of clothing is shown in Table 8. Calculating the amount of clothing worn by the subject using Equation (2) resulted in values of 0.35 clo for men and 0.45 clo for women. The metabolic rate of the subject was assumed to be 1.8 because the subject performed a driving simulation in a comfortable state and because of a simple question and answer.

Table 8. Garment insulation values.

\begin{tabular}{ccc}
\hline Garment Description $\left(\boldsymbol{I}_{\text {clo }}\right)$ & Man & Woman \\
\hline Briefs & 0.04 & 0.14 \\
\hline T-shirt & 0.11 & 0.11 \\
\hline Socks & 0.02 & 0.02 \\
\hline Straight trousers & 0.18 & 0.18 \\
\hline Total amount of clothing & 0.35 & 0.45 \\
\hline
\end{tabular}

\subsection{Experimental Method and Procedure}

The subject entered a preparation room at $25^{\circ} \mathrm{C}$, and the EEG sensor and PPG sensors were attached for $10 \mathrm{~min}$. Then, the basic waveforms of EEG and PPG were measured for $5 \mathrm{~min}$. The subjects then entered the psychrometric chamber, and a driving simulation was carried out by sitting in the driver's seat of a car simulator in the psychrometric chamber. The driving environment was set by using the old city map of the free driving mode as a software function. This was determined to be the most comfortable course, and the traffic regulations-including the speed limit-were similar to those of Korea. The weather conditions were set to clear, and the time was set to daytime. Subjects drove without restrictions on the driving course while observing traffic regulations in the city to 
investigate the variation of the emotional signals of the driver according to the cabin and vent discharge air temperature under actual driving conditions.

To simulate the climatic condition in the summer, the experimental condition of the indoor space was initially set to $35^{\circ} \mathrm{C}$, which was the indoor temperature of the vehicle when it was not operating. That could be an unpleasant condition for the driver. The solar light was installed to irradiate light on the body of the subject to simulate the solar radiation in summer. The recording of the EEG, PPG, and surface temperature of the subject was started to measure them during driving for $5 \mathrm{~min}$. After the measurement of these was finished, the driver parked the vehicle on the shoulder, and questionnaires were conducted on the thermal and comfort sensations of the subject. Because the first experimental condition was too hot and unpleasant for the driver, the experiment was conducted for only $5 \mathrm{~min}$. Then, the HVAC vent started to discharge cold air of $12.5^{\circ} \mathrm{C}$ under the same cabin temperature. The same process was carried out whenever the room temperature was lowered by a step of $2.5^{\circ} \mathrm{C}$, and the vent discharge air temperature was increased by a step of $2{ }^{\circ} \mathrm{C}$. The subject drove the car for $15 \mathrm{~min}$. The first $10 \mathrm{~min}$ involved adapting to driving and the temperature, and changes in the EEG, PPG, and skin temperature of the subject were measured during the last $5 \mathrm{~min}$. By repeatedly performing this process, bio-signals of the subjects were measured five times until the cabin and the vent discharge air temperatures were finally $22.5^{\circ} \mathrm{C}$.

The air flow rate from the vent in this cooling experiment was set to $450 \mathrm{~m}^{3} / \mathrm{h}$, which is the volume flow rate of air discharged from the air conditioner based on a $2000 \mathrm{cc}$ class passenger vehicle. The upper and lower parts of the vent were open as in the cooling mode in a typical passenger vehicle. Figure 4 shows the overall process and measurement time of this experiment, and Table 9 shows the setting temperature in each step. Figure 5 shows the actual experimental photograph. Subjective questionnaires for TSV, CSV, and CLV based on the American Society of Heating, Refrigerating and Air-Conditioning Engineers' (ASHRAE) specifications [34] were conducted simultaneously. Table 10 shows the questionnaires used. The subjective questionnaire regarding the thermal comfort satisfaction and concentration of the subject was conducted by a seven-step method. Generally, -3 for TSV, CSV, and CLV indicates cold, unpleasant, and a poor concentration state, while +3 for TSV, CSV, and CLV indicates hot, comfortable, and highly focused concentration.

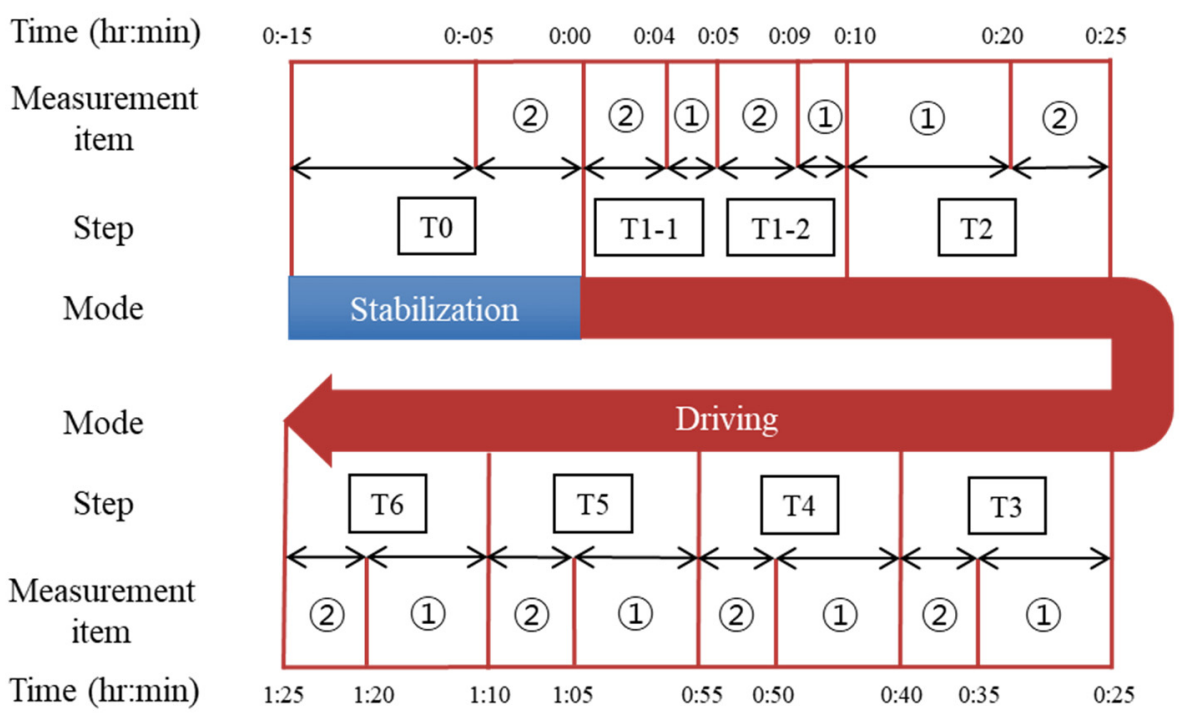

(1) Adaptation (2) Measuring of EEG, PPG, and surface temperature

Figure 4. Experimental procedure and measurement items. 
Table 9. Setting temperature for cooling mode.

\begin{tabular}{|c|c|c|c|c|}
\hline Mode & Wind Direction & Step & Cabin Temp. $\left({ }^{\circ} \mathrm{C}\right)$ & Vent Temp. $\left({ }^{\circ} \mathrm{C}\right)$ \\
\hline \multirow{8}{*}{ Cooling } & \multirow{8}{*}{ Body \& foot } & T0 & 25 & - \\
\hline & & T1-1 & 35 & - \\
\hline & & T1-2 & 35 & 12.5 \\
\hline & & $\mathrm{T} 2$ & 32.5 & 14.5 \\
\hline & & T3 & 30 & 16.5 \\
\hline & & $\mathrm{T} 4$ & 27.5 & 18.5 \\
\hline & & T5 & 25 & 20.5 \\
\hline & & T6 & 22.5 & 22.5 \\
\hline
\end{tabular}

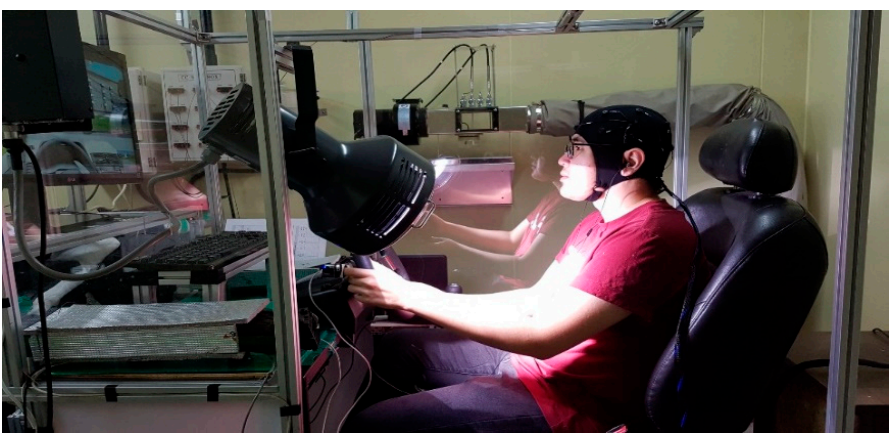

Figure 5. Photograph showing actual experimental state.

Table 10. Subjective questionnaires.

\begin{tabular}{|c|c|}
\hline \multicolumn{2}{|c|}{ Thermal Sensation Vote (TSV) } \\
\hline Value & Contents \\
\hline-3 & Very cold \\
\hline-2 & Cold \\
\hline-1 & Slightly cold \\
\hline 0 & Neutral \\
\hline 1 & Warm \\
\hline 2 & Slightly hot \\
\hline 3 & Very hot \\
\hline \multicolumn{2}{|c|}{ Comfort Sensation Vote (CSV) } \\
\hline Value & Contents \\
\hline-3 & Very uncomfortable \\
\hline-2 & Uncomfortable \\
\hline-1 & Slightly uncomfortable \\
\hline 0 & Neutral \\
\hline 1 & Slightly comfortable \\
\hline 2 & Comfortable \\
\hline 3 & Very comfortable \\
\hline \multicolumn{2}{|c|}{ Concentration Level Vote (CLV) } \\
\hline Value & Contents \\
\hline-3 & Very low concentration \\
\hline-2 & Low concentration \\
\hline-1 & Slightly low concentration \\
\hline 0 & Neutral \\
\hline 1 & Slight concentration \\
\hline 2 & Concentration \\
\hline 3 & Very concentration \\
\hline
\end{tabular}




\section{Results and Discussion}

\subsection{Analysis of Mean Surface Temperature of Subjects}

Figure 6 shows the variation of mean surface temperature (MST) of the driver according to the cabin and vent discharge air temperature under maximum and average solar radiations of 1251 and $516 \mathrm{~W} / \mathrm{m}^{2}$, respectively. A thermal-imaging camera was used to measure the surface temperature of the subject based on rainbow-based color coding. Red indicates a higher temperature, and purple represents a lower temperature. As shown in Figure $6 \mathrm{~b}$, when the cooling mode is not operated at a cabin temperature of $35^{\circ} \mathrm{C}$, the skin temperature of the subject shows a sky color, which represents a higher temperature. In particular, the surface temperature on the abdomen of the subject is highest because the solar light directly heats that part, and a wide area of red around the abdomen appears. Figure $6 \mathrm{c}$ shows the surface temperature of the subject when HVAC with a vent discharge air temperature of $12.5^{\circ} \mathrm{C}$ was operated at the same cabin temperature of $35^{\circ} \mathrm{C}$. The surrounding colors of the subject are mainly sky-blue and blue, which means a decrease in the surrounding temperature of the subject. In addition, the color of the air near the vent is purple, which represents a low temperature. The abdomen where the radiation is concentrated and its surroundings appear yellow and green compared with that when the cooling vent is not operated. The surface temperature of the subject rapidly decreases when the vent cooling is operated. As the temperature of the cabin decreases, the ambient temperature and the surface temperature of the subject decreases, and they are mostly blue when the cabin and vent discharge air temperatures are $30.5 \mathrm{and} 16.5^{\circ} \mathrm{C}$, respectively, as shown in Figure 6e. The yellow area decreases and the green area increases in the abdomen and body of the subject. Then, the ambient temperature and the surface temperature of the subject decrease continuously until the cabin and vent discharge air temperature of $22.5^{\circ} \mathrm{C}$. When the cabin and vent discharge air temperature is $22.5^{\circ} \mathrm{C}$, the surrounding air is purple, indicating the lowest temperature. The largest decrease in surface temperature is observed in the abdomen. This is because the cooling effect is the most effective in the abdomen because the cold air blowing from the vent outlet directly contacts the surface of the subject, and the surface temperature is the highest because of solar illumination.

Figure 7 shows the variation in the average surface temperature on the left hand, right hand, forehead, and abdomen of the subjects by using the thermal-imaging camera during cooling in a car. At the common room temperature of $25^{\circ} \mathrm{C}$, the average surface temperature on the left hand, right hand, forehead, and abdomen of the subject were 28.6, 28.9, 31.5, and $30.1{ }^{\circ} \mathrm{C}$, respectively. When the cabin temperature was $35^{\circ} \mathrm{C}$ without the vent cooling operation, the average surface temperatures on the left hand, right hand, forehead, and abdomen increased significantly to $37.9,36.6,36.5$, and $47.4{ }^{\circ} \mathrm{C}$, respectively. In addition, the temperature on the abdomen was the highest compared with other surface areas because the solar light irradiated intensely on the abdomen under a cabin temperature of $35^{\circ} \mathrm{C}$; however, the surface temperatures of the subjects, except for the abdomen, were similar. When the vent discharge air temperature was $12.5^{\circ} \mathrm{C}$ under a cabin air temperature of $35^{\circ} \mathrm{C}$, the average surface temperatures on the left hand, right hand, forehead, and abdomen of the subjects were $37.0,34.5,34.5$, and $41.6{ }^{\circ} \mathrm{C}$, respectively. By using vent cooling, the surface temperature of the forehead and abdomen of the subject during driving decreased by 3.0 and $11.5^{\circ} \mathrm{C}$, respectively. The surface temperature of the forehead and abdomen of the subject can be reduced noticeably because of the low discharge air temperature of $12.5^{\circ} \mathrm{C}$, despite a high cabin temperature of $35^{\circ} \mathrm{C}$. Thereafter, the surface temperatures of the subjects gradually decrease as the cabin temperature decreases; however, the decrement of surface temperatures is not significant. 


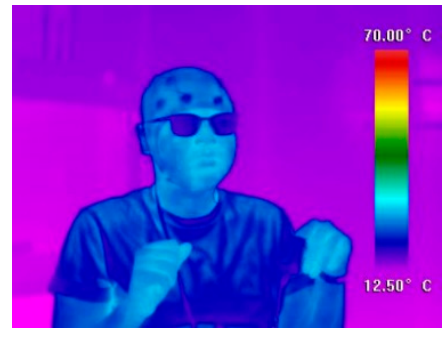

(a)

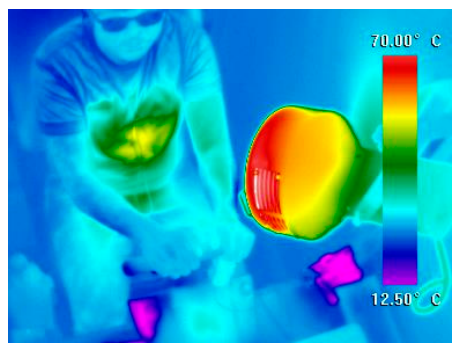

(d)

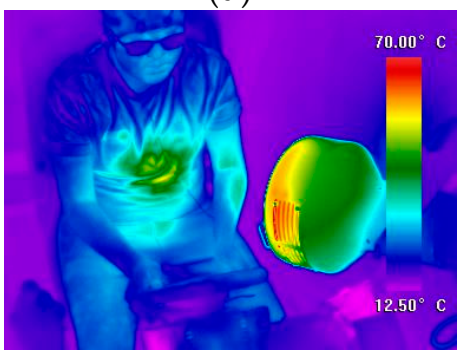

(g)

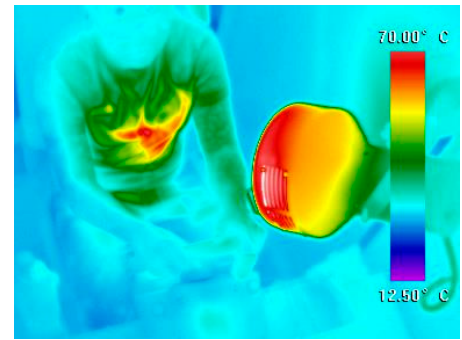

(b)

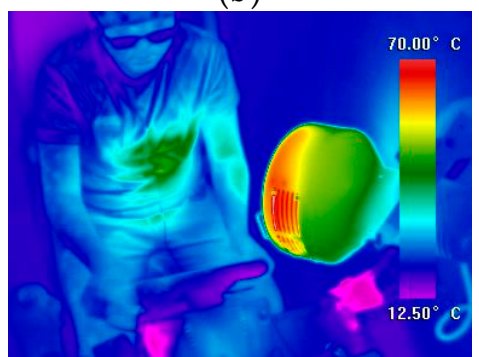

(e)

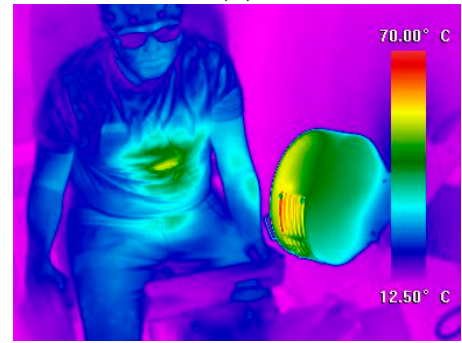

(h)

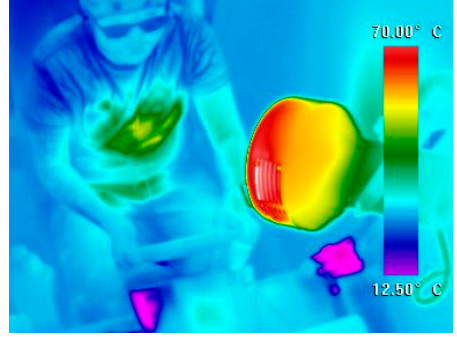

(c)

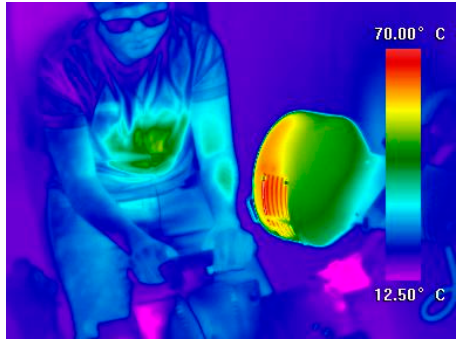

(f)

Figure 6. Photographs of driver's thermal imaging in cooling mode. (a) Cabin $25^{\circ} \mathrm{C} / \mathrm{Non}-\mathrm{Vent}$; (b) Cabin $35^{\circ} \mathrm{C} / \mathrm{Non}$-Vent; (c) Cabin $35^{\circ} \mathrm{C} /$ Vent $12.5^{\circ} \mathrm{C}$; (d) Cabin $32.5^{\circ} \mathrm{C} /$ Vent $14.5^{\circ} \mathrm{C}$; (e) Cabin $30^{\circ} \mathrm{C} /$ Vent $16.5^{\circ} \mathrm{C}$; (f) Cabin $27.5^{\circ} \mathrm{C} /$ Vent $18.5^{\circ} \mathrm{C}$; (g) Cabin $25^{\circ} \mathrm{C} /$ Vent $20.5^{\circ} \mathrm{C}$; (h) Cabin $22.5^{\circ} \mathrm{C} /$ Vent $22.5^{\circ} \mathrm{C}$.

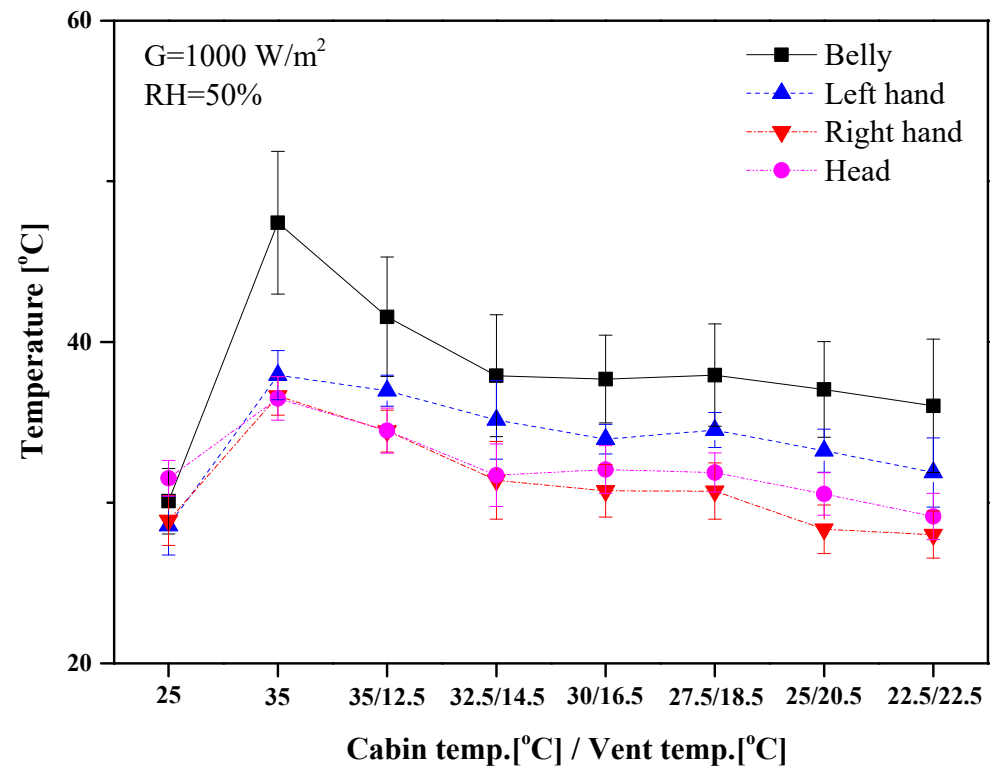

Figure 7. Variation of driver's mean skin temperature in the cooling mode.

The average surface temperature on the left hand, right hand, forehead, and abdomen of the subject decreased to $31.9,28.0,29.2$, and $36.0^{\circ} \mathrm{C}$, respectively, in the cabin and at a vent discharge air temperature of $22.5^{\circ} \mathrm{C}$. In particular, the temperature on the abdomen and left hand was significantly reduced because of the cooling effect on the abdomen and 
left hand being relatively high. These parts have higher temperatures because they are directly exposed to the irradiating solar light and are in direct contact with the cold vent discharge air.

\subsection{Analysis of Questionnaire (TSV, CSV, and CLV) Results}

Figure 8 shows the results of the questionnaires of the average TSV, CSV, and CLV of subjects according to the cabin and vent discharge air temperature under solar radiation. The TSV was 2.89 at a cabin temperature of $35^{\circ} \mathrm{C}$ without vent cooling, which shows that subjects felt very hot. The TSV was significantly reduced to 1.33 when the HVAC with a vent discharge temperature of $12.5^{\circ} \mathrm{C}$ was operated at a cabin temperature of $35^{\circ} \mathrm{C}$. That means that the thermal sensation of the subjects decreased from very hot to warm. At the cabin and vent discharge air temperatures of 30 and $16.5^{\circ} \mathrm{C}$, the TSV was 0 , and it was confirmed that the subjects were in a thermally neutral state. Next, the TSV value gradually decreased as the cabin and vent discharge air temperatures were changed to $22.5^{\circ} \mathrm{C}$, and the subjects at a cabin and vent discharge air temperature of $22.5^{\circ} \mathrm{C}$ were in a cold state because the TSV was -2.11 .

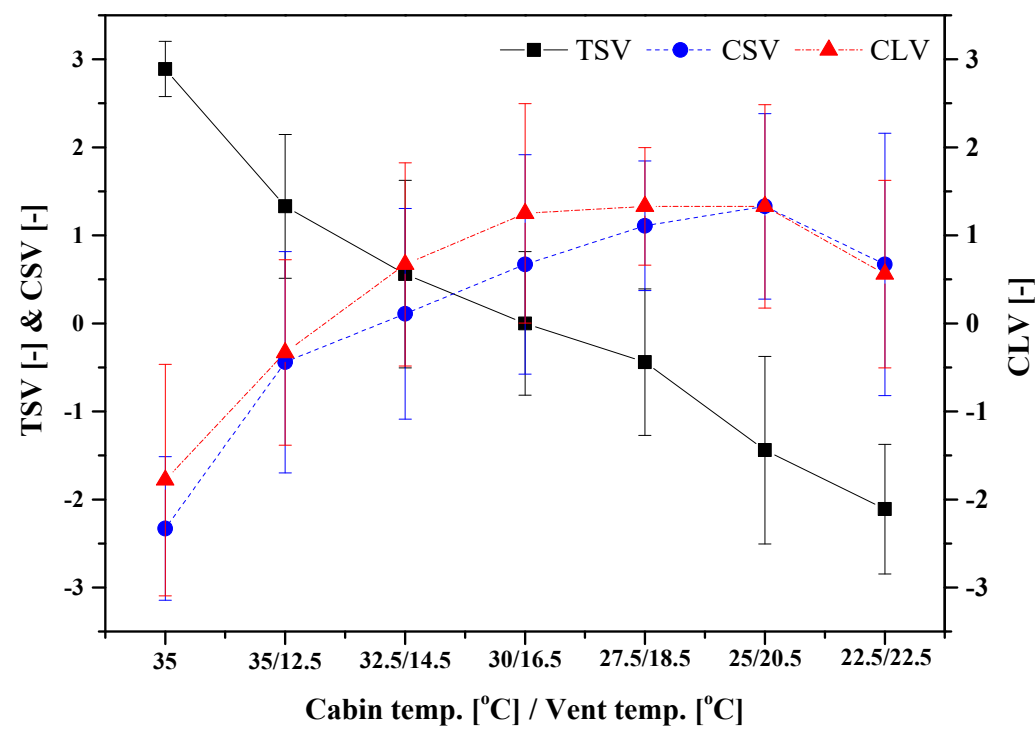

Figure 8. Variations of TSV, CSV, and CLV questionnaires.

In the results of the CSV questionnaire, the CSV at a cabin temperature of $35{ }^{\circ} \mathrm{C}$ without vent cooling operation was -2.33 , which was the lowest. This value indicated that the subjects felt great discomfort because of the high cabin temperature. When the cooling was operated with a vent discharge temperature of $12.5^{\circ} \mathrm{C}$ under a cabin temperature of $35^{\circ} \mathrm{C}$, the CSV increased rapidly to -0.44 , and the comfort sensation of subjects was similar to the neutral state. The subjects felt suddenly comfortable compared with the previous condition because the discharge air from the vent with a low temperature of $12.5^{\circ} \mathrm{C}$ could quickly provide a comfortable environment to the driver, even though it was a hot cabin environment $\left(35^{\circ} \mathrm{C}\right)$. Then, the CSV increased up to cabin and vent discharge air temperatures of 25 and $20.5^{\circ} \mathrm{C}$, respectively. The CSV at cabin and vent discharge air temperatures of 25 and $20.5^{\circ} \mathrm{C}$ was 1.33 , which was the highest value recorded; thus, the survey result found that subjects felt the most comfortable in this condition. Next, the CSV decreased to 0.67 at a cabin and vent discharge air temperature of $22.5^{\circ} \mathrm{C}$. A cabin and vent discharge air temperature of $22.5^{\circ} \mathrm{C}$ is relatively cold because of the direct contact of the low temperature air to the body of the driver.

According to the results of the CLV questionnaire of the subjects during cooling in the indoor environment of the car, the CLV was the lowest. It was -1.78 at a cabin temperature of $35^{\circ} \mathrm{C}$ without the vent cooling operation. During vent cooling with a low discharge air temperature of $12.5^{\circ} \mathrm{C}$, the CLV rapidly increased to -0.33 . This is because of the operation 
of vent cooling with a low temperature of $12.5^{\circ} \mathrm{C}$ despite a hot cabin temperature of $35^{\circ} \mathrm{C}$. The vent cooling provided a thermally pleasant environment to the driver and greatly improved concentration during driving. As the cabin temperature decreased, the CLV tended to increase, and the CLV increased to 1.33 at cabin and vent discharge air temperatures of 25 and $20.5^{\circ} \mathrm{C}$, respectively. However, when the cabin and vent discharge air temperatures were $22.5^{\circ} \mathrm{C}$, the CLV decreased to 0.56 , which means the subjects felt cold and unpleasant, and the concentration of the drivers decreased owing to long-term driving. The CLV showed a similar result to that of the CSV. In the overall results of the subjective questionnaires (TSV, CSV, and CLV), the subjects were comfortable and had a high level of concentration in the temperature ranges of the cabin and vent discharge air temperatures of 30 and $16.5^{\circ} \mathrm{C}$ to those of 25 and $20.5^{\circ} \mathrm{C}$, respectively.

\subsection{Analysis Results of PPG Measurement}

Figure 9 shows the variation of the pulse wave of the driver according to the cabin and vent discharge air temperatures in the cooling mode under solar radiation. Figure 9a shows the variations of the stress index, TP, and LF/HF. At room temperature $\left(25^{\circ} \mathrm{C}\right)$, which was the preparation condition before the experiment, the stress index, TP, and LF/HF showed general values, because it was the common indoor temperature. Unlike the results of questionnaires, the stress index, TP, and LF/HF did not change significantly when the cabin and vent discharge air temperatures were 35 and $12.5^{\circ} \mathrm{C}$, respectively. This may be because it was too short a time after the subject started to drive, and the bodies' response to feeling was not immediately linked to the pulse wave. Thus, the pulse wave of subjects did not change immediately according to the operating condition. After the body adapted for a certain period at a high temperature, the stress index increased rapidly at the cabin and vent discharge air temperatures of 32.5 and $14.5^{\circ} \mathrm{C}$, respectively. Accordingly, TP tended to decrease slightly. This indicates that the ability of the driver to regulate the external environment change and to cope with stress deteriorate during a long time under high temperatures, which also results in an increase in the stress index of the driver. At cabin and vent discharge air temperatures of 30 and $16.5^{\circ} \mathrm{C}$, the TP increased and the stress index decreased; therefore, it can be judged that the subjects were relatively stable and comfortable when driving under this condition. However, the stress index rapidly increased again at cabin and vent discharge air temperatures of 25 and $20.5^{\circ} \mathrm{C}$.

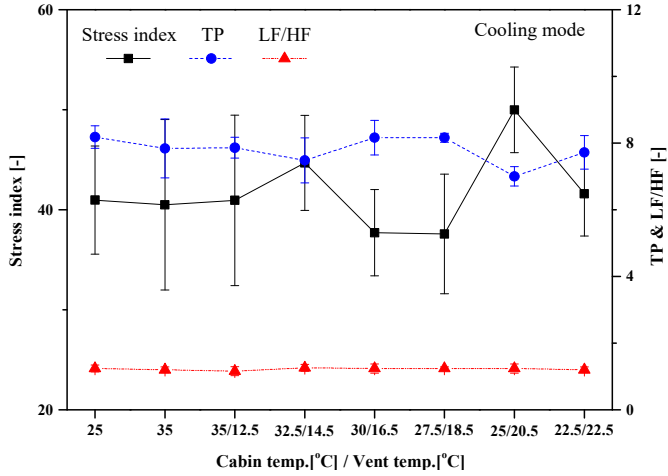

(a)

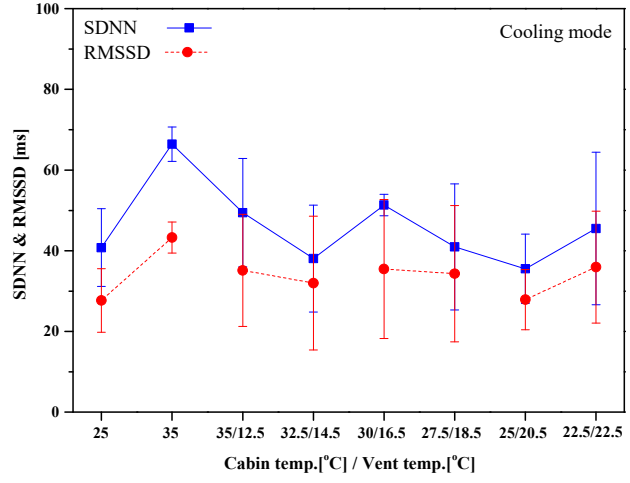

(b)

Figure 9. Variations in driver's PPG in cooling condition. (a) stress index, total power (TP), and LF/HF; (b) the standard deviation of N-N interval (SDNN) and root mean square of successive differences (RMSSD).

The discomfort of the driver was caused by the direct contact with a low air temperature and the fatigue from a long driving time. The result of the PPG analysis confirmed that there was a time gap between the emotional feeling and the PPG reaction during driving.

Figure $9 \mathrm{~b}$ shows the variations in the SDNN and RMSSD in the pulse wave of the subjects during driving. The SDNN and RMSSD at a cabin temperature of $35^{\circ} \mathrm{C}$ without vent cooling were higher than those at the indoor temperature of $25^{\circ} \mathrm{C}$, which was the 
preparation condition. This is because the subject suddenly entered a hot environment and the body temperature of the subject increased rapidly. This phenomenon occurred at the stage of human body adaptation in a hot environment. Afterwards, the cabin temperature tended to decrease continuously until the cabin and vent discharge air temperatures of 32.5 and $14.5^{\circ} \mathrm{C}$, respectively, which means that the driver felt uncomfortable under these temperature conditions. SDNN and RMSSD at cabin and vent discharge air temperatures of 30 and $16.5^{\circ} \mathrm{C}$ increased slightly, which is similar to the variation in the stress index. This was because the body of the driver adapted to the thermal environment, which provided a relatively comfortable environment to the driver. In the results of the PPG analysis under a cooling condition with solar radiation in the summer, the stress index of the driver decreased at cabin and vent discharge air temperatures of 30 and $16.5^{\circ} \mathrm{C}$, as well as 27.5 and $18.5^{\circ} \mathrm{C}$, respectively, while the TP, SDNN, and RMSSD increased simultaneously. Therefore, these two temperature conditions can provide a relatively comfortable driving environment for the driver. Shin et al. [31] conducted an experiment on the variation of bio-signals of drivers according to the cabin temperature inside the car without solar load, and they reported that the cabin and vent discharge air temperatures were set to 27.5 and $18.5^{\circ} \mathrm{C}$, respectively, to improve driver comfort and concentration in the cooling mode. These cabin and vent discharge air temperatures suggested as comfortable temperature conditions in the previous study were slightly different from the result of this study. In this study, it is recommended that the cabin and vent discharge air temperatures be set to 30 and $16.5^{\circ} \mathrm{C}$, respectively. The solar radiation effect on the driver causes the driver to feel hotter; thus, the driver feels cooler and more comfortable when a vent with a discharged air temperature of $16.5^{\circ} \mathrm{C}$ is working, even though the cabin temperature is slightly higher than that without solar radiation.

\subsection{Analysis Results of EEG Measurement}

Figure 10 shows the EEG analysis results in the prefrontal lobe of the subject according to the cabin and vent discharge air temperature with an average solar radiation of $516 \mathrm{~W} / \mathrm{m}^{2}$. Figure 10 a shows the variations of the relative $\theta$-wave, SMR wave, $\beta$-wave and $\mathrm{CI}$, and $\beta / \alpha$ in the prefrontal lobe of the driver. At the indoor temperature of $25{ }^{\circ} \mathrm{C}$, the relative $\theta$-wave was high, while the relative SMR and $\beta$-wave were relatively low. The relative $\theta$-wave was the highest because the drivers were sitting on a chair in a comfortable environment at a ready state. Moreover, because there was no fatigue for driving, the relative SMR and $\beta$-wave values were also the lowest. The relative $\theta$-wave decreased and relative SMR and $\beta$-wave slightly increased when the subject started to drive at a cabin temperature of $35^{\circ} \mathrm{C}$ without vent cooling. This is because the body of the subject felt uncomfortable when the driver moved from a comfortable condition to a hot condition. However, it was considered a relatively small change because of the delay of the body response to adapt to this condition for the sudden temperature change. The relative SMR wave was the highest at cabin and vent discharge air temperatures of 30 and $16.5{ }^{\circ} \mathrm{C}$ because the experiment was conducted continuously under high-temperature conditions. The relative SMR wave shows the concentration and slight tension of the driver. In these temperature ranges, the subject was in a state of slight tension; thus, the subject was considered to have a high level of concentration during driving. Afterwards, at a cabin and vent discharge air temperature of $22.5^{\circ} \mathrm{C}$, the relative $\theta$-wave increased, while the relative SMR and $\beta$-wave tended to decrease. This means that the fatigue of the driver increased because of the long driving time and drowsiness; thus, the concentration during driving was reduced. 


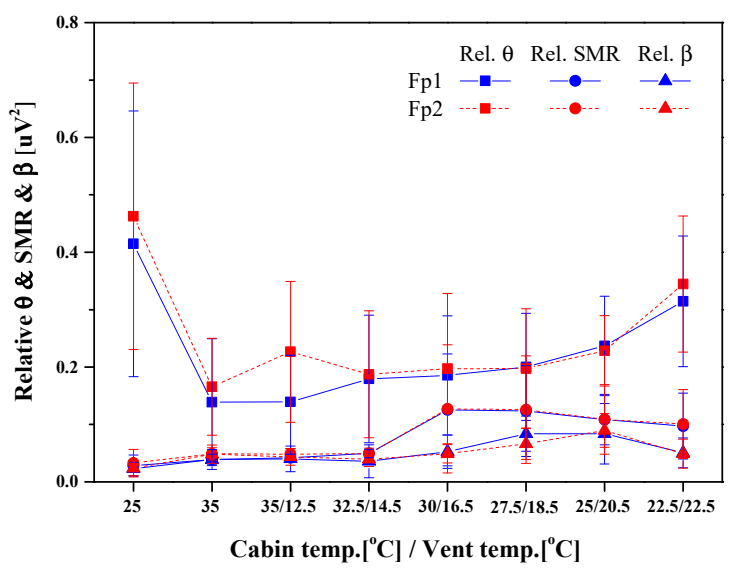

(a)

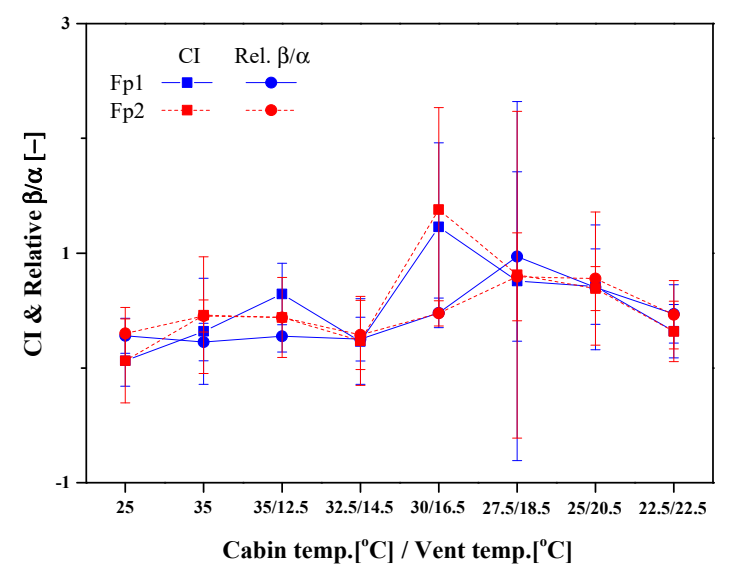

(b)

Figure 10. Variations of concentration index (CI), relative $\beta / \alpha_{-}, \theta-$, sensory motor rhythm (SMR), and $\beta$-waves at the prefrontal lobe. (a) Relative $\theta$-wave, SMR, and $\beta$-wave; (b) CI and relative $\beta / \alpha$-wave.

The relative $\theta-$, SMR, and $\beta$-waves are the indicators of the concentration of the subject. Based on these values, the concentration index (CI) and relative $\beta / \alpha$ at the prefrontal lobe were calculated, as shown in Figure $10 \mathrm{~b}$. At an indoor temperature of $25{ }^{\circ} \mathrm{C}$, the concentration was the lowest, and the relative $\beta / \alpha$ was also low because the subject was in a comfortable state and doing nothing. The concentration showed a tendency to increase when the driver started to drive at a cabin temperature of $35^{\circ} \mathrm{C}$ without vent cooling, and the relative $\beta / \alpha$ also increased. Concentration increased at first because of the focus on driving by the subject. The reason for the increase in the relative $\beta / \alpha$ is that the subject was nervous because of discomfort caused by the high-temperature environment without vent cooling. Both the concentration and relative $\beta / \alpha$ of subjects were relatively low at cabin and vent discharge air temperatures of 32.5 and $14.5^{\circ} \mathrm{C}$, respectively, because the driver felt comfortable; however, the concentration on driving was reduced, owing to slight drowsiness. When the cabin and vent discharge air temperatures were 30 and $16.5^{\circ} \mathrm{C}$, concentration was the highest, and the relative $\beta / \alpha$ showed an increasing trend. When the cabin and vent discharge air temperatures were 25 and $20.5^{\circ} \mathrm{C}$, concentration tended to decrease, and the relative $\beta / \alpha$ was the highest. This is considered to be a condition that requires the driver to rest because the concentration of the subject during driving was reduced due to a long driving time and the high stress during driving.

Figure 11 displays the relative $\alpha$ - and $\beta$-waves of the driver in the occipital lobe according to the cabin and vent discharge air temperature with a maximum and average solar radiation of 1251 and $516 \mathrm{~W} / \mathrm{m}^{2}$, respectively. The relative $\alpha$-wave was high at the $25^{\circ} \mathrm{C}$ preparation condition, and it slightly increased at a cabin temperature of $35^{\circ} \mathrm{C}$ without vent cooling. Under this condition, the relative $\beta$-wave increased slightly, but it was not a meaningful change because the increase in the relative $\beta$-wave was not significant. Thereafter, the relative $\alpha$-wave decreased continuously until the cabin and vent discharge air temperatures were 27.5 and $18.5^{\circ} \mathrm{C}$, respectively, while the relative $\beta$-wave value tended to increase. This means the subject was focusing on driving. Therefore, the relative $\alpha$-wave that appeared under a relaxed state, such as relaxation of tension, decreased, and the relative $\beta$ wave increased. After the cabin and vent discharge air temperatures were 25 and $20.5^{\circ} \mathrm{C}$, the relative $\alpha$-wave increased, and the relative $\beta$-wave decreased. This was because the concentration of the subject was slightly reduced because of slight drowsiness and the increase in fatigue after driving for a long time. 


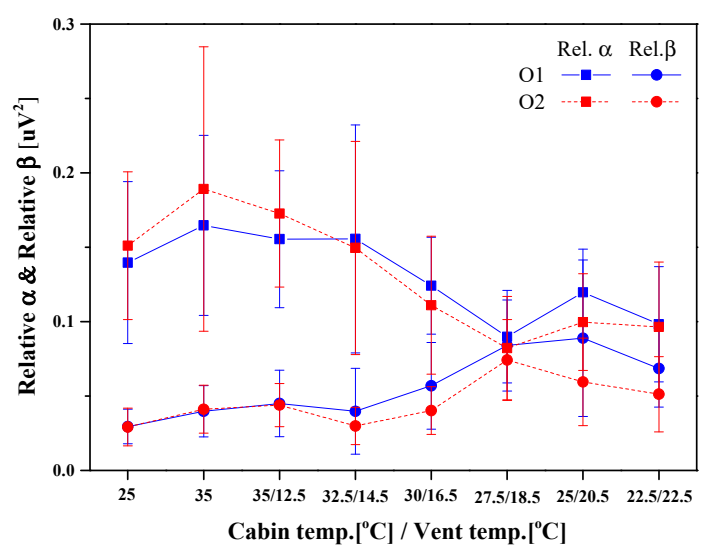

(a)

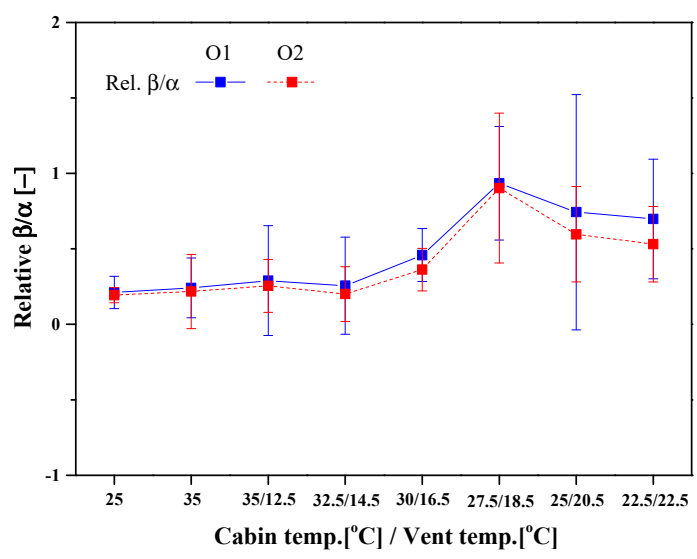

(b)

Figure 11. Variations of relative $\beta / \alpha_{-}, \alpha_{-}$, and $\beta$-waves at the occipital lobe. (a) Relative $\alpha$ and $\beta$; (b) Relative $\beta / \alpha$.

The cabin and vent discharge air temperatures were 27.5 and $18.5^{\circ} \mathrm{C}$, respectively, while the relative $\beta$-wave value tended to increase. This means the subject was focusing on driving. Therefore, the relative $\alpha$-wave that appeared under a relaxed state, such as relaxation of tension, decreased, and the relative $\beta$ wave increased. After the cabin and vent discharge air temperatures were 25 and $20.5{ }^{\circ} \mathrm{C}$, the relative $\alpha$-wave increased, and the relative $\beta$-wave decreased. This was because the concentration of the subject was slightly reduced because of slight drowsiness and the increase in fatigue after driving for a long time.

\section{Conclusions}

In this study, the bio-signals (EEG, PPG, and skin temperature) of subjects were measured, and subjective surveys (TSV, CSV, and CLV) were conducted for the indoor environment of cars in summer conditions to investigate the thermal comfort of drivers under solar radiation, according to the cabin and vent discharge air temperatures. The following conclusions were obtained.

(1) In the measurement result for the mean surface temperature, when a vent discharge air temperature of $12.5^{\circ} \mathrm{C}$ was used at a cabin temperature of $35^{\circ} \mathrm{C}$, the average surface temperatures on the forehead, left hand, right hand, and abdomen of the subject decreased by $2,0.97,2.18$, and 5.86 , respectively.

(2) In the results of the subjective survey, the TSV decreased significantly from 2.89 to 1.33 when the vent with a discharge air temperature of $12.5^{\circ} \mathrm{C}$ was operated at a cabin temperature of $35^{\circ} \mathrm{C}$. In addition, the CSV increased from -2.33 to -0.44 and the CLV increased from -1.78 to -0.33 under the same condition. The vent cooling provided a thermally pleasant environment for the driver and greatly improved the concentration on the driving. The CSV and CLV at cabin and vent discharge air temperatures of 25 and $20.5{ }^{\circ} \mathrm{C}$ were 1.33 and 1.33 , respectively, which were the highest; thus, drivers felt the most comfortable in this condition.

(3) In the PPG experimental results, TP, SDNN, and RMSSD increased and the stress index decreased at cabin and vent discharge air temperatures of 30 and $16.5^{\circ} \mathrm{C}$ and 27.5 and $18.5^{\circ} \mathrm{C}$, respectively. This means that the subject was relatively stable and comfortable driving under these conditions. In the results of the EEG experiment, the relative SMR wave in the frontal lobe was highest at the cabin and vent discharge air temperatures of 30 and $16.5^{\circ} \mathrm{C}$, respectively. Under this condition, the subject was in a state of slight tension, which is considered to result in the highest concentration during driving. When the cabin and vent discharge air temperatures were 25 and $20.5^{\circ} \mathrm{C}$, respectively, the concentration decreased and the relative $\beta / \alpha$ was the highest; therefore, the concentration on driving of the subject was slightly reduced owing to a long driving time and some fatigue during driving. 
(4) In the results of the bio-signal analysis (MST, PPG, and EEG) of the driver, the driving concentration was high at cabin and vent discharge air temperatures of $30-27.5^{\circ} \mathrm{C}$ and $16.5-18.5^{\circ} \mathrm{C}$, respectively. However, the results of the subjective surveys (TSV, CSV, and CLV) showed that the driver was comfortable and had high concentration during driving at cabin and vent discharge air temperatures of $30-25^{\circ} \mathrm{C}$ and $16.5-$ $20.5^{\circ} \mathrm{C}$, respectively. Therefore, the results of the bio-signals of the human body may be slightly different from feelings of subjects because of the differences between the reaction of the body and feelings for temperature changes of the environment.

(5) As comprehensively analysis of the subjective survey, PPG, and EEG results, TP, SDNN, and RMSSD of subjects increased and stress index decreased at the cabin and vent discharge air temperatures of $30-27.5^{\circ} \mathrm{C}$ and $16.5-18.5^{\circ} \mathrm{C}$, respectively. Besides, the relative SMR wave and CI index of the frontal lobe tended to increase under same temperature conditions. Accordingly, it was confirmed that these temperature conditions provided a pleasant driving environment to the driver and increased the concentration on driving.

Author Contributions: Conceptualization, Y.S. and J.H.; methodology Y.S. and H.C.; validation, H.C., Y.S.; formal analysis, J.H.; investigation, J.H. and Y.S.; resources, H.C.; writing—original draft preparation, J.H.; writing —review and editing, Y.S. and H.C.; visualization, J.H.; supervision, H.C. All authors have read and agreed to the published version of the manuscript.

Funding: This research was supported by the Basic Science Research Program through the National Research Foundation of Korea (NRF) funded by the Ministry of Science, ICT and Future Planning (NRF-2020R1A2C2008248) and Human Resources Program in Energy Technology of the Korea Institute of Energy Technology Evaluation and Planning (KETEP), granted financial resources from the Ministry of Trade, Industry and Energy, Republic of Korea (No. 20194030202410).

Informed Consent Statement: Informed consent was obtained from all subjects involved in the study.

Conflicts of Interest: The authors declare no conflict of interest.

\section{References}

1. Commercializations Promotion Agency for R\&D Outcomes, S\&T Market Report, Autonomous Vehicle. Commer. Promot. Agency RED Outcomes 2018, 65, 1-19.

2. Lee, S.M. Recent Trends and Implications of Autonomous Vehicles. Inst. Inf. Commun. Technol. Plan. Eval. Wkly. Technol. Trend 2018, 1842, 16-23.

3. Mao, Y.; Wang, J.; Li, J. Experimental and numerical study of air flow and temperature variations in an electric vehicle cabin during cooling and heating. Appl. Therm. Eng. 2018, 137, 356-367. [CrossRef]

4. Korea Joongang Daily. Available online: https:/ / news.joins.com/article/22754265 (accessed on 28 June 2018).

5. Hong, S.H.; Kim, M.E.; Kim, M.H. Thermal environment analysis and thermal comfort evaluation of the automobile interior. Mag. SAREK 2006, 35, 34-45.

6. Yao, Y.; Lian, Z.; Liu, W.; Shen, Q. Experimental study on physiological responses and thermal comfort under various ambient temperatures. Physiol. Behav. 2008, 93, 310-321. [CrossRef]

7. Ciuha, U.; Mekjavic, I.B. Regional thermal comfort zone in males and females. Physiol. Behav. 2016, 161, 123-129. [CrossRef]

8. Ciuha, U.; Tobita, K.; McDonnell, A.C.; Mekjavic, I.B. The effect of thermal transience on the perception of thermal comfort. Physiol. Behav. 2019, 210, 112623. [CrossRef]

9. Ciuha, U.; Mekjavic, I.B. Thermal comfort zone of the hands, feet and head in males and females. Physiol. Behav. 2017, 179, 427-433. [CrossRef]

10. Lai, D.; Zhou, X.; Chen, Q. Measurements and predictions of the skin temperature of human subjects on outdoor environment. Energy Build. 2017, 151, 476-486. [CrossRef]

11. Chang, P.F.; Arendt-Nielsen, L.; Chen, A.C.N. Comparative cerebral responses to non-painful warm vs. cold stimuli in man: EEG power spectra and coherence. Int. J. Psychophysiol. 2005, 55, 73-83. [CrossRef]

12. Hodder, S.G.; Parsons, K. The effects of solar radiation on thermal comfort. Int. J. Biometeoral. 2007, 51, 233-250. [CrossRef] [PubMed]

13. Chien, H.; Jang, J.Y.; Chen, Y.H.; Wu, S.C. 3-D numerical and experimental analysis for airflow within a passenger compartment. Int. J. Automot. Technol. 2008, 9, 437-445. [CrossRef]

14. Martinho, N.A.G.; Silva, M.C.G.; Ramos, J.A.E. Evaluation of thermal comfort in a vehicle cabin. Proc. Inst. Mech. Eng. Part D J. Automob. Eng. 2004, 218, 159-166. [CrossRef] 
15. Lin, C.H.; Han, T.; Koromilas, C.A. Effects of HVAC design parameters on passenger thermal comfort. SAE Technical. Pap. 1992, 920264. [CrossRef]

16. Kobayashi, Y.T.K.; Mori, Y.J.; Yoshimura, S.N.C.; Tanabe, S.N.C.; Oi, H.J.M. Thermal comfort in car cabin with cooling individual body parts. In Proceedings of the 10th International Conference on Healthy Buildings, Brisbane, Australia, 8-12 July 2012; Volume 2, p. 1030.

17. Zhang, H.; Lan, D.; Xu, G.; Li, Y.; Chen, W.; Tao, W.Q. Studies of air-flow and temperature fields inside a passenger compartment for improving thermal comfort and saving energy. Part I: Test/numerical model and validation. Appl. Therm. Eng. 2009, 29, 2022-2027. [CrossRef]

18. Zhang, H.; Lan, D.; Xu, G.; Li, Y.; Chen, W.; Tao, W.Q. Studies of air-flow and temperature fields inside a passenger compartment for improving thermal comfort and saving energy. Part II: Simulation results and discussion. Appl. Therm. Eng. 2009, 29, 2028-2036. [CrossRef]

19. Zhou, X.; Lai, D.; Chen, Q. Experimental investigation of thermal comfort in a passenger car under driving conditions. Build. Environ. 2019, 149, 109-119. [CrossRef]

20. Qi, C.; Helian, Y.; Liu, J.; Zhang, L. Experiment study on the thermal comfort inside a car passenger compartment. Procedia Eng. 2017, 205, 3607-3614. [CrossRef]

21. Jung, W.; Jazizadeh, F. Comparative assessment of HVAC control strategies using personal thermal comfort and sensitivity models. Build. Environ. 2019, 158, 104-119. [CrossRef]

22. Kristanto, D.; Leephakpreeda, T. Sensitivity analysis of energy conversion for effective energy consumption, thermal comfort, and air quality within car cabin. Energy Procedia 2017, 138, 552-557. [CrossRef]

23. Alahmer, A.; Abdelhamid, M.; Omar, M. Design for thermal sensation and comfort states in vehicles cabins. Appl. Therm. Eng. 2012, 36, 126-140. [CrossRef]

24. Alahmer, A.; Omar, M.; Mayyas, A.R.; Qattawi, A. Analysis of vehicular cabins' thermal sensation and comfort state, under relative humidity and temperature control, using Berkeley and Fanger models. Build. Environ. 2012, 48, 146-163. [CrossRef]

25. Alahmer, A.; Mayyas, A.; Mayyas, A.A.; Omar, M.A.; Shan, D. Vehicular thermal comfort models; a comprehensive review. Appl. Therm. Eng. 2011, 31, 995-1002. [CrossRef]

26. Ting, P.H.; Hwang, J.R.; Doong, J.L.; Jeng, M.C. Driver fatigue and highway driving: A simulator study. Physiol. Behav. 2008, 94, 448-453. [CrossRef] [PubMed]

27. Tsutsumi, H.; Hoda, Y.; Tanabe, S.; Arishiro, A. Effect of Car Cabin Environment on Driver's Comfort and Fatigue. SAE Technical. Pap. 2007, 116, 335-346.

28. Shin, Y.; Im, G.; Yu, G.; Cho, H. Experimental study on the change in driver's physiological signals in automobile HVAC system under Full-load condition. Appl. Therm. Eng. 2017, 112, 1213-1222. [CrossRef]

29. Shin, Y.; Ham, J.; Cho, H. Investigation on thermal comfort using driver's bio-signals depend on vehicle cabin and vent exit air temperature. J. Mech. Sci. Technol. 2019, 33, 3585-3596. [CrossRef]

30. Ikenishi, T.; Kamada, T.; Nagia, M. Analysis of longitudinal driving behaviors during car following situation by the driver's EEG using PARAFAC. IFAC Proc. Vol. 2013, 46, 415-422. [CrossRef]

31. Yang, L.; Ma, R.; Zhang, H.M.; Guan, W.; Jiang, S. Driving behavior recognition using EEG data from a simulated car-following experiment. Accid. Anal. Prev. 2018, 116, 30-40. [CrossRef]

32. DuBois, D.; DuBois, E.F. A formula to estimate approximate surface area, if height and weight are known. Ann. Intern. Med. 1916, 17, 863-871. [CrossRef]

33. McCullough, E.A.; Jone, B.W.; Huck, J. A Comprehensive Data Base for Estimating Clothing Insulation; IER Technical Report, 84-01; ASHRAE Research Project RP-411, Final Report; Institute for Environmental Research, Kansas State University: Manhattan, KS, USA, 1984.

34. Thermal Environmental Conditions for Human Occupancy. In ANSI/ASHRAE Addendum b to ANSI/ASHRAE Standard 55-2013; ASHRAE: Atlanta, GA, USA, 2014; ISSN 1041-2336. 